\title{
THE RELATION BETWEEN AMINO ACIDS AND POTASSIUM IN ISOLATED RAT MUSCLE *
}

\author{
By NORMAN.G. LEVINSKY,† IAN TYSON, \\ ARNOLD S. RELMAN WITH THE TECHNICAL ASSISTANCE OF
} ARLENE M. ROY

\author{
(From the Evans Memorial Department of Clinical Research, Massachusetts Memorial \\ Hospitals, and the Department of Medicine, Boston University School \\ of Medicine, Boston, Mass.)
}

(Submitted for publication September 21, 1961 ; accepted October 23, 1961)

In previous studies in this laboratory, using intact rat diaphragms incubated in an artificial medium free of amino acids, it was found that there was essentially no change in steady-state muscle potassium in vitro as external potassium was lowered from 5.5 to $1.1 \mathrm{mEq}$ per $\mathrm{L}$ (1). By contrast, when plasma potassium fell to comparable levels in vivo in potassium-deficient rats, diaphragm potassium content was reduced by about one-third. It was therefore concluded that reduction in external potassium concentration alone is insufficient to produce the loss of muscle potassium observed in potassium-deficient rats. Since the striking difference between the in vivo and in vitro behavior of skeletal muscle could not be explained by changes in extracellular acid-base balance, it was evident that other unidentified factors must play a role.

A number of observations suggested that cationic amino acids might be among these unidentified factors. Qualitative studies by Iacobellis, Muntwyler and Dodgen (2) had shown that the amount of lysine and arginine in the muscle of potassiumdepleted rats was grossly increased. Quantitative analyses by Eckel, Norris and Pope (3) indicated that about one-third of the potassium lost from such muscle was replaced by cationic amino acids,

\footnotetext{
* Submitted in honor of Chester S. Keefer, M. D., and the Golden Anniversary of the Evans Memorial Department of Clinical Research, Boston, Mass. Aided by the National Institutes of Health, Grant H2767, and by a grant from the Muscular Dystrophy Associations of America, Inc. Presented in part at the Annual Meeting of the American Society for Clinical Investigation, May 1960.

$\dagger$ During tenure as a Special Fellow of the U. S. Public Health Service, and subsequently as a Fellow of the Medical Foundation, Inc., Boston, Mass.

$\$$ Trainee of the National Institute of Arthritis and Metabolic Diseases.

$\S$ Postdoctoral Fellow, National Heart Institute.
}

principally lysine. Furthermore, an extensive series of experiments from Christensen's laboratory had demonstrated an intimate relation between amino acid and potassium metabolism in Ehrlich ascites tumor cells (4). Consideration of these data led us to investigate the effect of cationic amino acids on potassium metabolism in our in vitro mammalian muscle preparation.

\section{METHODS}

Groups of intact diaphragms taken from 40 to $80 \mathrm{~g}$ Sprague-Dawley rats were incubated in modified KrebsRinger bicarbonate solution ( $\mathrm{pH}$ approximately 7.4) gassed with a mixture of 95 per cent oxygen and 5 per cent carbon dioxide, to which varying amounts of potassium chloride and amino acid were added. The details of this technique have been reported previously (1). Experiments were of three types.

1. In the first type the steady-state relation between muscle potassium and amino acid content was evaluated in the presence of various external potassium and amino acid concentrations. Diaphragms were incubated for periods of at least 8 hours, after which groups of muscles were removed from the medium at intervals in order to verify that muscle potassium and amino acid content remained constant during a subsequent period of at least 3 hours. The mean values of potassium and amino acid content of muscles removed during this 3-hour period were designated the steady-state muscle potassium and amino acid content.

2. The second type of experiment was designed to study the influence of external amino acid concentration on the rate of net reaccumulation of muscle potassium. Diaphragms previously leached of potassium were allowed to reaccumulate potassium in media containing various concentrations of potassium. Paired experiments were carried out in the presence and absence of amino acid. During the reaccumulation period paired groups of diaphragms were removed from the media at frequent intervals.

3. The third type of experiment was designed to evaluate the rates of net gain or loss of amino acid by the muscles. First, to study the rate of net accumulation of 
amino acid by the muscles, diaphragms were removed in groups at short intervals from media containing various concentrations of potassium and amino acid. Second, to examine the rate of net loss of muscle amino acid content, diaphragms incubated initially in media rich in amino acid were then placed in media free of amino acid and removed in groups at intervals.

After incubation, diaphragms were rapidly dissected from the rib cage and the wet weight of each hemidiaphragm was obtained separately. In all experiments one hemidiaphragm of each pair was used for determinations of potassium and water content and, when necessary, for sodium, chloride, and inulin analyses by methods previously described (1). The other hemidiaphragm was rapidly frozen and later used to estimate free cationic amino acid content. Its dry weight was calculated by assuming its water content to be that determined for the other member of the pair.

To analyze muscle for its content of free cationic amino acid, the tissue was thawed, homogenized in 10 per cent sodium tungstate and $0.083 \mathrm{~N}$ sulfuric acid mixture, and then centrifuged. Duplicate $0.1-$ or $0.2-\mathrm{ml}$ aliquots of the supernate were taken for electrophoretic separation of cationic amino acid, as described by Eckel and colleagues ${ }^{1}$ (3), except that a commercial electrophoretic apparatus was used. In earlier experiments the colorimetric ninhydrin determination of cationic amino acid was carried out as described by Eckel and coworkers (3). In later experiments it was found more convenient to use a minor modification of the photometric ninhydrin method of Moore and Stein (5). Recovery of cationic amino acid from muscle by this latter method was $102.1 \pm 4.3$ per cent, compared with a mean recovery of $95.0 \pm 3.6$ per cent by the former method. The difference between the means was not statistically significant $(\mathrm{p}>0.05)$.

Throughout this paper, statistical significance has been evaluated by the Fisher $t$ test. Differences between means described as significant gave a $p$ value of less than 0.01 .

\section{RESULTS}

Effect of various amino acids on steady-state potassium content. Amino acids were maintained at the concentrations listed in Table I for the entire 8- to 12-hour period of incubation. External potassium concentration was approximately $1 \mathrm{mEq}$ per $L$ in all experiments, which is the minimal concentration adequate to maintain a normal steady-state tissue content of potassium (1).

As shown in Table I, the effect of an amino acid on steady-state potassium content depends in part upon the charge on the amino acid. At the concentrations employed. cationic amino acids had

1 The authors are grateful to Dr. Eckel for his advice in the development of this modification of his method.
TABLE I

Effect of amino acids on steady-state potassium content of rat diaphragm incubated at external potassium of $1 \mathrm{mEq}$ per

\begin{tabular}{|c|c|c|c|}
\hline Amino acid & $\begin{array}{l}\text { Bath } \\
\text { conc. } \\
\text { of amino } \\
\text { acid }\end{array}$ & $\begin{array}{c}\text { Tissue } \\
\mathrm{K} \text { content }\end{array}$ & $\underset{\text { phragms }}{\text { Dia- }}$ \\
\hline & mmoles $/ L$ & $\begin{array}{c}m E q / 100 \\
g \text { dry wt }\end{array}$ & no. \\
\hline None & & $36 \pm 2^{*}$ & 45 \\
\hline \multicolumn{4}{|l|}{ Cationic amino acids } \\
\hline $\begin{array}{l}\text { Arginine } \\
\text { Histidine } \\
\text { Lysine } \\
\text { Ornithine } \\
\text { Diaminobutyric acid }\end{array}$ & $\begin{array}{l}8 \\
8 \\
8 \\
8 \\
3\end{array}$ & $\begin{array}{l}24 \pm 5 \\
28 \pm 2 \\
22 \pm 2 \\
28 \pm 2 \\
27 \pm 1\end{array}$ & $\begin{array}{l}47 \\
24 \\
21 \\
12 \\
12\end{array}$ \\
\hline \multicolumn{4}{|l|}{ Neutral amino acids } \\
\hline $\begin{array}{l}\text { Glycine } \\
\text { Methionine } \\
\text { Phenylalanine } \\
\text { Alanine }\end{array}$ & $\begin{array}{l}8 \\
8 \\
6 \\
7\end{array}$ & $\begin{array}{l}32 \pm 2 \\
32 \pm 2 \\
34 \pm 1 \\
32 \pm 4\end{array}$ & $\begin{array}{l}11 \\
11 \\
11 \\
12\end{array}$ \\
\hline \multicolumn{4}{|l|}{ Anionic amino acids } \\
\hline $\begin{array}{l}\text { Aspartic acid } \\
\text { Glutamic acid }\end{array}$ & $\begin{array}{l}8 \\
8\end{array}$ & $\begin{array}{l}35 \pm 3 \\
35 \pm 3\end{array}$ & $\begin{array}{l}22 \\
24\end{array}$ \\
\hline \multicolumn{4}{|l|}{ Primary diamine } \\
\hline Cadaverine & 4 & $30 \pm 2$ & 12 \\
\hline
\end{tabular}

* Mean \pm standard deviation.

a marked and significant depressant effect on potassium content. This was true for diamino-butyric acid and the diamine, cadaverine (decarboxylated lysine), as well as for the common diaminomonocarboxylic amino acids. Neutral amino acids had a significant but less marked depressant effect on potassium content. Anionic amino acids had no effect.

Lysine was selected to evaluate in more detail the effect of cationic amino acids on tissue potassium content because it had been found to be the principal amino acid present in potassium-depleted rat muscle (3). The mean steady-state potassium content of muscles incubated for 8 to 12 hours at various external potassium and lysine concentrations is summarized in Table II and plotted in Figure 1. The points in the figure are to be compared with the broken line which describes potassium content in the absence of lysine (1). Note that potassium content in the absence of lysine is virtually constant between an external potassium of 1 and $9 \mathrm{mEq}$ per L. The standard deviations and number of diaphragms for each mean value plotted in Figure 1 are listed in Table II. 
The data show that, at a fixed level of external potassium, progressive increases in external lysine up to 4 to 8 mmoles per $\mathrm{L}$ result in successive reductions in steady-state potassium content. Moderate increases in lysine concentration in the medium beyond 8 mmoles per $\mathrm{L}$ have little or no further effect. Conversely, for a given external lysine concentration, the lower the external potassium concentration (within the range of 1 to 9 $\mathrm{mEq}$ per $\mathrm{L}$ ) the greater the loss of tissue potassium. In the two experiments in which the external potassium was less than $1 \mathrm{mEq}$ per $\mathrm{L}$, the effect of lysine on tissue potassium was equivocal. As shown in Figure 1 the tissue potassium content in each experiment was close to that to be expected in the absence of lysine at the respective external potassium concentrations employed. However, because of the steep slope of the line relating tissue content to external potassium concentration at these very low external concentrations, a small effect of lysine might be difficult to detect.

Relation between muscle lysine content and decrease in tissue potassium. Lysine analyses were performed on most of the tissues shown in Figure 1 , and the results are given in the right-hand column of Table II. The relation between lysine

TABLE II

Effect of various external potassium and lysine concentrations on steady-state tissue content of potassium and lysine

\begin{tabular}{|c|c|c|c|c|c|}
\hline \multirow{2}{*}{\multicolumn{2}{|c|}{$\frac{\begin{array}{c}\text { External } \\
\text { concentrations }\end{array}}{\text { Potassium Lysine }}$}} & \multicolumn{4}{|c|}{ Tissue content } \\
\hline & & \multicolumn{2}{|c|}{ Potassium } & \multicolumn{2}{|c|}{ Lysine } \\
\hline \multicolumn{2}{|c|}{ mmoles /L } & \multicolumn{4}{|c|}{ mmoles $/ 100 \mathrm{~g} \mathrm{dry} \mathrm{wt}$} \\
\hline 0.08 & .8 & $11 \pm 3 *$ & $(10) \dagger$ & $13+2 *$ & $(10) \dagger$ \\
\hline 0.4 & 8 & $-18 \pm 2$ & (10) & $14 \pm 2$ & (10) \\
\hline $\begin{array}{l}1.0 \\
1.0 \\
1.0 \\
1.0 \\
1.0 \\
1.0 \\
1.0\end{array}$ & $\begin{array}{l}0 \\
0.8 \\
2 \\
4 \\
8 \\
12 \\
16\end{array}$ & $\begin{array}{l}36 \pm 2 \\
31 \pm 3 \\
29 \pm 3 \\
26 \pm 3 \\
22 \pm 2 \\
22 \pm 2 \\
23 \pm 2\end{array}$ & $\begin{array}{l}(45) \\
(101) \\
(64) \\
(22) \\
(21) \\
(10) \\
(11)\end{array}$ & $\begin{array}{r}4 \pm 1 \\
6 \pm 1 \\
8 \pm 2 \\
13 \pm 3 \\
15 \pm 3 \\
14 \pm 3\end{array}$ & $\begin{array}{l}(42) \\
(49) \\
(18) \\
(17) \\
(10) \\
(11)\end{array}$ \\
\hline $\begin{array}{l}\mathbf{5 . 0} \\
\mathbf{5 . 0} \\
\mathbf{5 . 0} \\
\mathbf{5 . 0} \\
\mathbf{5 . 0} \\
\mathbf{5 . 0}\end{array}$ & $\begin{array}{l}\mathbf{0} \\
\mathbf{0 . 8} \\
2 \\
\mathbf{4} \\
\mathbf{8} \\
16\end{array}$ & $\begin{array}{l}38 \pm 2 \\
35 \pm 2 \\
32 \pm 3 \\
30 \pm 3 \\
28 \pm 3 \\
26 \pm 1\end{array}$ & $\begin{array}{l}(30) \\
(23) \\
(24) \\
(24) \\
(24) \\
(10)\end{array}$ & $\begin{array}{r}3 \pm 1 \\
6 \pm 1 \\
8 \pm 2 \\
10 \pm 3 \\
17 \pm 3\end{array}$ & $\begin{array}{l}(11) \\
(24) \\
(17) \\
(18) \\
(9)\end{array}$ \\
\hline $\begin{array}{l}9.0 \\
9.0 \\
9.0 \\
9.0 \\
9.0\end{array}$ & $\begin{array}{r}0 \\
2 \\
4 \\
8 \\
16\end{array}$ & $\begin{array}{l}39 \pm 2 \\
34 \pm 3 \\
31 \pm 3 \\
30 \pm 3 \\
30 \pm 3\end{array}$ & $\begin{array}{l}(35) \\
(35) \\
(22) \\
(23) \\
(34)\end{array}$ & $\begin{array}{r}5 \pm 1 \\
7 \pm 2 \\
10 \pm 2 \\
11 \pm 2\end{array}$ & $\begin{array}{l}(24) \\
(11) \\
(12) \\
(33)\end{array}$ \\
\hline
\end{tabular}

* Mean \pm standard deviation.

$\dagger$ Number of analyses in parentheses.

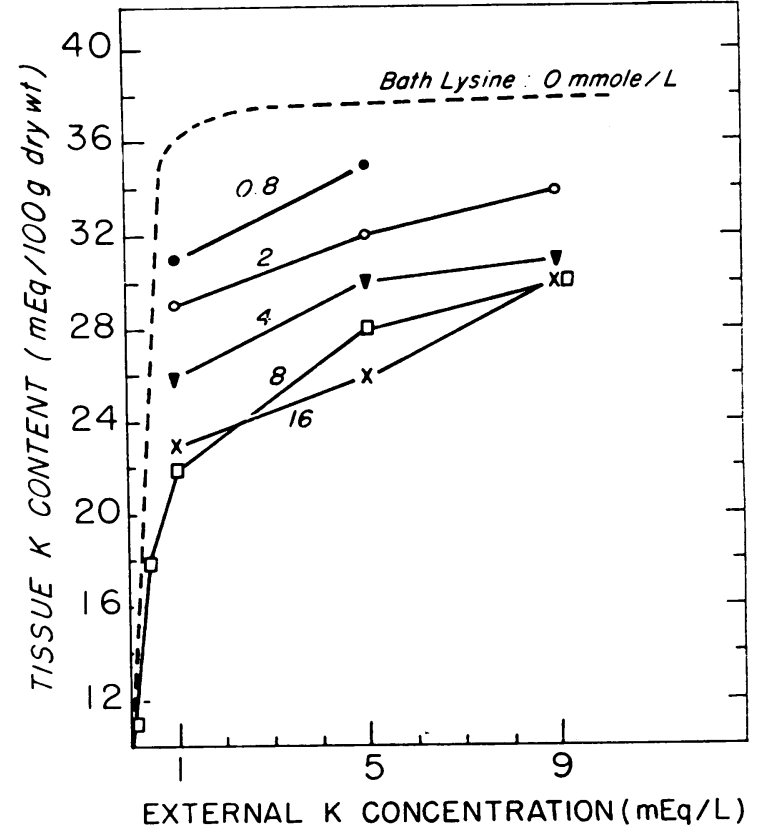

Fig. 1. Tissue potassium content at various exTERNAL POTASSIUM AND LYSINE CONCENTRATIONS. Each point represents the mean steady-state potassium content of a group of diaphragms incubated in a medium containing lysine, the concentration of which is indicated by the number alongside each curve. The number of diaphragms and standard deviation for each group are listed in Table II. The broken line represents steady-state potassium content of diaphragms incubated in a lysine-free medium (1).

content and decrease in potassium is shown in Figure 2. The decrease in potassium content in each group of diaphragms in Figure 2 was calculated by subtracting the mean potassium content of that group of diaphragms from the mean of a group of diaphragms incubated at a comparable external potassium but without lysine (Table II). The broken line bisecting the graph defines equality between the two variables. It is obvious from the data that there is approximate equivalence between potassium loss and amino acid content over the entire range of concentration studied.

Intracellular electrolyte and water content of muscle incubated in the presence and absence of lysine. The approximate equivalence of lysine content and decrease in potassium content suggests that lysine displaces potassium as cation for cation from intracellular water. This implies that no net change in other electrolytes or water content occurs when muscles are incubated in the 


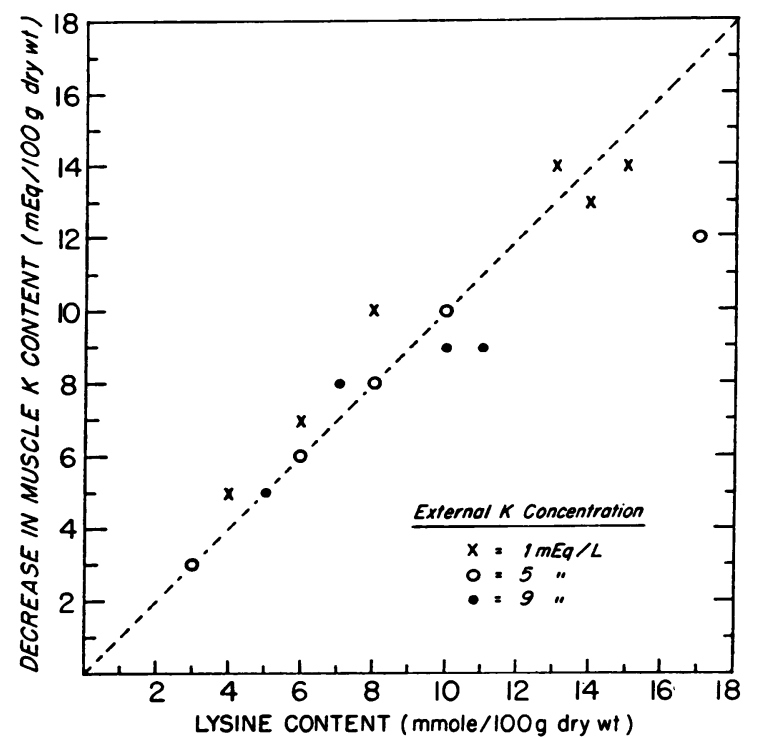

Fig. 2. Relation BetweEn MUSCle LySine AND DECREASE IN POTASSIUM CONTENT. Each point represents the mean lysine content and decrease in potassium content of one group of diaphragms in Table II. All the groups incubated in media containing lysine and potassium at a concentration of 1 or more $\mathrm{mEq}$ per $\mathrm{L}$ are plotted in this figure. The broken line indicates the relation which would hold if potassium loss were equivalent to lysine content.

presence of lysine. To verify this prediction experiments were undertaken in which inulin was added to the incubation medium so that water compartments and intracellular electrolytes could be calculated. The results of these experiments are summarized in Table III. In the top half of this table are shown the results of paired experiments at an external potassium of $1 \mathrm{mEq}$ per $\mathrm{L}$ with and without lysine. There is apparently one-for-one replacement of intracellular potassium by lysine. ${ }^{2}$ This exchange is clearly seen from the fact that the sum of intracellular potassium plus lysine was essentially the same in both experiments. As expected, intracellular sodium and chloride did not change significantly.

In the bottom half of Table III are shown the results of paired experiments at an external potassium concentration of $9 \mathrm{mEq}$ per $\mathrm{L}$ with and without lysine. The major change is again a stoichiometric replacement of potassium by lysine, as shown by the relative constancy of the sums of potassium and lysine content. There is, however, a small but statistically significant increase in intracellular chloride, although the increase in intracellular sodium is not significant. Water content and distribution did not change significantly.

Reaccumulation of tissue potassium in the presence and absence of amino acids. A number of experiments was performed in an effort to determine whether competition for entrance at the cell membrane accounts for the relation between lysine gain and potassium loss. In order to evaluate the effect of amino acid on potassium reaccumulation, diaphragms were first depleted of potassium by leaching in potassium-free media for approximately 4 hours, after which time a group of dia-

\footnotetext{
2 It should be noted that the determination of lysine content of tissue incubated without lysine in the external medium was not performed in this particular series of experiments. However, many determinations of lysine content of unincubated diaphragms gave a value of approximately $1 \mathrm{mmole}$ per $100 \mathrm{~g}$ dry weight, or approximately 4 mmoles per $\mathrm{L}$ of intracellular water. This datum has therefore been inserted in the appropriate positions in Table III.
}

TABLE III

Steady-state intracellular electrolyte and water content of rat diaphragm incubated at high and low potassium concentration with and without lysine

\begin{tabular}{|c|c|c|c|c|c|c|c|c|c|}
\hline \multicolumn{2}{|c|}{$\begin{array}{c}\text { External } \\
\text { concentrations } \\
\end{array}$} & \multirow[b]{2}{*}{ Analyses } & \multicolumn{5}{|c|}{ Int racellular electrolytes } & \multirow{2}{*}{$\begin{array}{l}\text { Intracell. } \\
\text { water }\end{array}$} & \multirow{2}{*}{$\begin{array}{c}\text { Extracell. } \\
\text { water }\end{array}$} \\
\hline $\mathrm{K}$ & Lysine & & $\mathrm{Na}$ & $\mathrm{K}$ & Lysine & $\mathrm{K}+$ Lys. & $\mathrm{Cl}$ & & \\
\hline \multicolumn{2}{|c|}{ mmoles $/ L$} & no. & \multicolumn{5}{|c|}{ mmoles $/ L$ intracellular water } & \multicolumn{2}{|c|}{$m l / 100 \mathrm{~g} d r y w t$} \\
\hline $\begin{array}{l}1 \\
1\end{array}$ & $\begin{array}{l}0 \\
2\end{array}$ & $\begin{array}{l}22 \\
31\end{array}$ & $\begin{array}{l}23 \pm 7^{*} \\
20 \pm 8\end{array}$ & $\begin{array}{l}148 \pm 8 \\
129 \pm 7\end{array}$ & $28^{4 \dagger} \pm 5$ & $\begin{array}{l}152 \\
157\end{array}$ & $\begin{array}{l}6 \pm 3 \\
6 \pm 5\end{array}$ & $\begin{array}{l}239 \pm 10 \\
226 \pm 12\end{array}$ & $\begin{array}{l}106 \pm 18 \\
102 \pm 12\end{array}$ \\
\hline $\begin{array}{l}9 \\
9\end{array}$ & $\begin{array}{r}0 \\
16\end{array}$ & $\begin{array}{l}15 \\
23\end{array}$ & $\begin{array}{l}11 \pm 5 \\
15 \pm 8\end{array}$ & $\begin{array}{l}167 \pm 8 \\
126 \pm 11\end{array}$ & $\begin{array}{c}4 \dagger \\
40 \pm 8\end{array}$ & $\begin{array}{l}171 \\
166\end{array}$ & $\begin{array}{r}4 \pm 4 \\
15 \pm 6\end{array}$ & $\begin{array}{l}230 \pm 15 \\
220 \pm 7\end{array}$ & $\begin{array}{l}116 \pm 14 \\
106 \pm 10\end{array}$ \\
\hline
\end{tabular}

* Mean \pm standard deviation

t See text. 


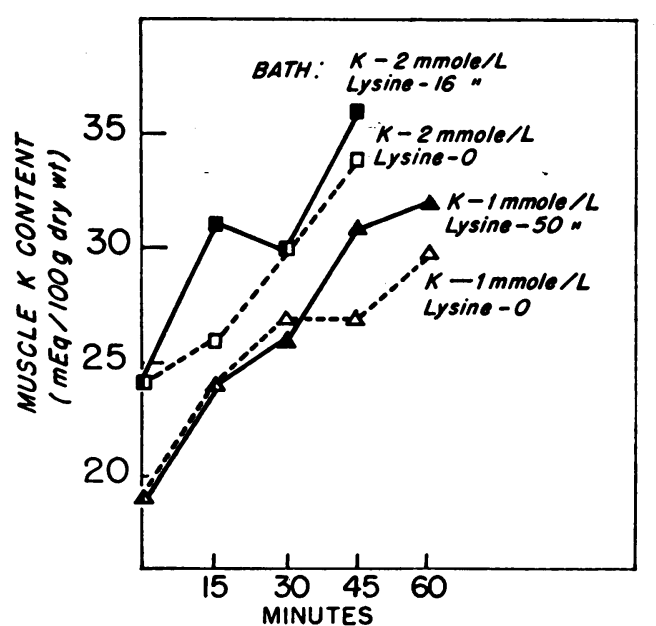

Fig. 3. Reaccumulation of tissue potassium in THE PRESENCE AND ABSENCE OF LySINE. Two paired experiments are shown. One experiment is represented by the upper two lines, the other by the lower two. In each experiment the symbols at zero time represent the tissue potassium content achieved by leaching diaphragms in potassium-free media for approximately 4 hours. In the upper experiment (square symbols) half the diaphragms (solid squares) were then placed in a medium containing 2 mmoles per $\mathrm{L}$ potassium, and 16 mmoles per L lysine; the other half (open squares) was placed in a medium containing 2 mmoles per $\mathrm{L}$ potassium, but no lysine. In the lower experiment (triangles) after leaching of potassium, half the diaphragms (solid triangles) were placed in a medium containing 1 mmole per L potassium, and 50 mmoles per L lysine; the other half (open triangles) was placed in a medium containing 1 mmole per $L$ potassium, but no lysine. Each symbol represents the mean potassium content of a group of two or three diaphragms.

phragms was removed for analysis. The remaining diaphragms were divided into two groups. One group was placed in a potassium-rich, amino acid-free medium, the other in a potassium-rich medium containing amino acid. Diaphragms were removed at intervals from each group. Four experiments were performed with lysine, three with the neutral amino acid glycine, and two with mixtures of amino acids simulating the variety and proportions found in rat plasma $(3,6)$.

The results of two representative experiments performed with lysine are shown in Figure 3. A1though there is some scatter in the data, probably occasioned by the small number of diaphragms at each point (two or three), there is no evidence that lysine significantly depresses the rate of potassium reaccumulation. Qualitatively similar results were obtained in the other experiments of this type.

The relatively crude methods employed preclude the demonstration of possible small differences. However, the over-all impression from these nine experiments is that amino acids in the external medium have no marked effect on the rate of potassium reaccumulation.

It should be noted in Figure 3 that the diaphragm content of potassium rises at the end of 45 or 60 minutes to more than $30 \mathrm{mEq}$ per $100 \mathrm{~g}$ dry weight, despite the presence of high concentrations of lysine in the bath. This does not contradict the observations in Table $I$ and Figure 1, because data to be shown below, as well as a number of tissue lysine determinations from these reaccumulation experiments, demonstrate that the rate of lysine accumulation is such that no more than about 5 mmoles will accumulate in 1 hour, and thus only a small depression of tissue potassium would be expected at this time. Apparently, cel-

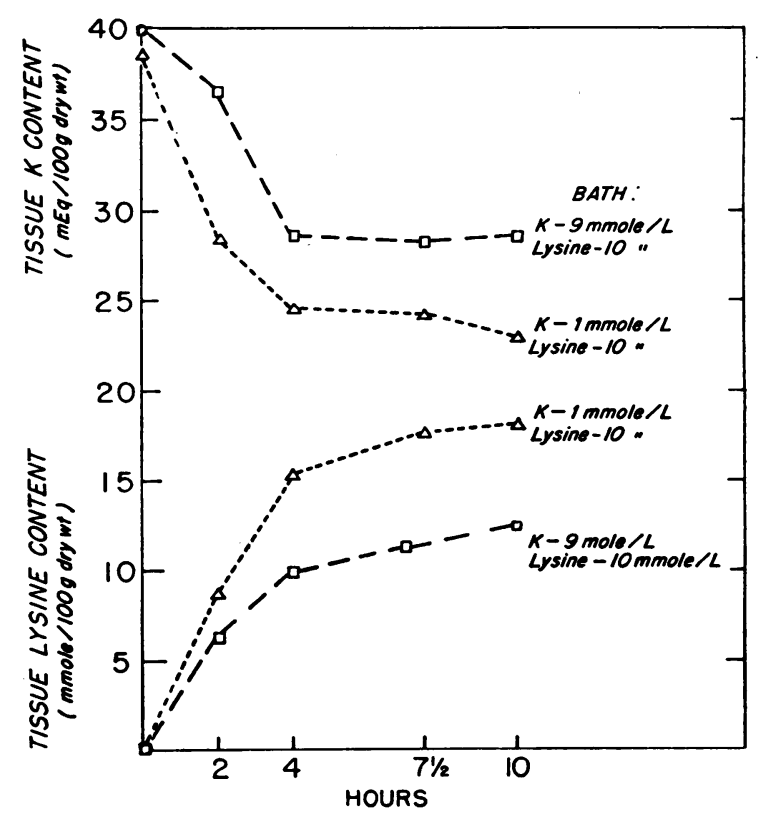

Fig. 4. Rate of accumulation of lysine and loss of Potassium. The mean tissue potassium and lysine content of groups of three diaphragms removed at intervals from two separate bathing media are plotted. Each medium contained 10 mmoles per L lysine. One medium contained $9 \mathrm{mEq}$ per $\mathrm{L}$ potassium (mean lysine and potassium content of these tissues represented by squares), and the other $1 \mathrm{mEq}$ per $\mathrm{L}$ potassium (triangles). 
lular potassium will not be lost without the simultaneous uptake of an equivalent amount of lysine. Accumulation and loss of lysine. Two experiments were undertaken to obtain a general idea of the rate of lysine accumulation. Tissues were incubated at an external lysine concentration of 10 mmoles per $\mathrm{L}$ and at external potassium concentrations of 1 and $9 \mathrm{mEq}$ per L. Groups of three diaphragms were removed and analyzed for lysine and potassium at $2,4,7.5$, and 10 hours. Figure 4 illustrates the results of both experiments. The figure shows that lysine accumulation requires at least 4 hours to reach equilibrium and that an approximately equivalent exchange of potassium for lysine is present throughout the course of the experiment.

Another two experiments were performed to obtain a rough estimate of the rate of loss of lysine by tissues previously allowed to accumulate this

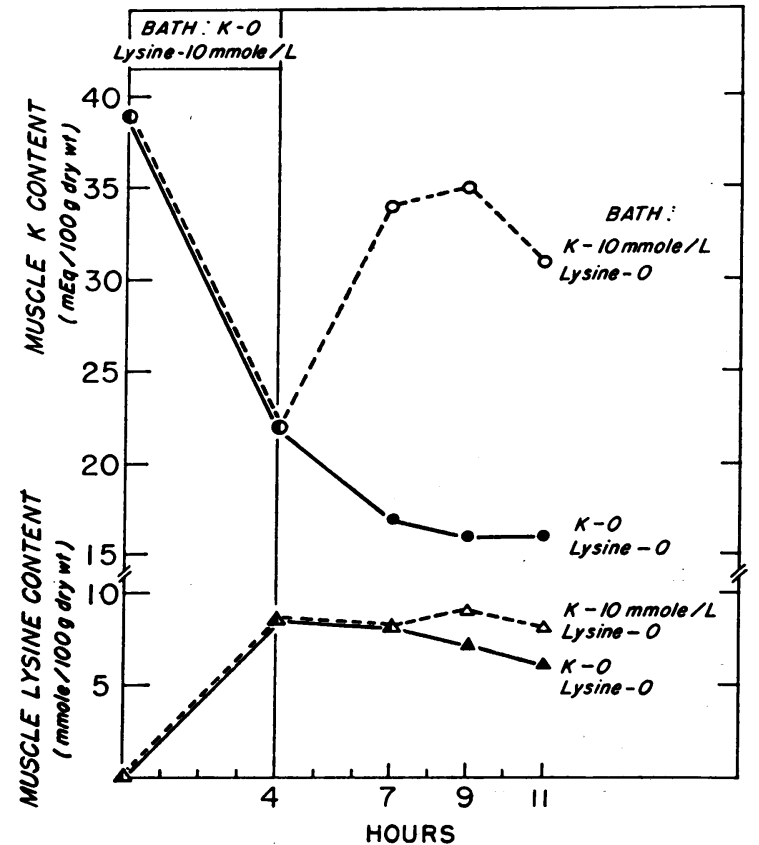

Fig. 5. RATE of LOSS OF LySine FROM MUSCles CONTAINING LYSINE. Changes in muscle potassium and lysine during two experiments are shown. One experiment is represented by broken lines, the other by solid lines. As shown on the left, in each experiment the tissues were initially loaded with lysine by 4 hours of incubation in a potassium-free, lysine-rich medium. In each case tissues were then placed in a lysine-free bath; one medium contained potassium (broken lines), the other did not (solid lines). The mean potassium or lysine content of three to four muscles is shown by each symbol. amino acid. Tissues were incubated for 4 hours in a potassium-free ${ }^{3}$ medium containing $10 \mathrm{mmoles}$ per $\mathrm{L}$ of lysine. At the end of this time some tissues were removed for lysine and potassium analysis, and the remainder was divided into two groups. One group was placed in a medium free of potassium and lysine and the other in a lysine-free medium containing $10 \mathrm{mEq}$ per $\mathrm{L}$ of potassium. Groups of three or four muscles were then removed at intervals for lysine and potassium analyses. As is shown in Figure 5 the rate of loss of lysine in both media is very slow as compared with the rate of lysine accumulation shown in Figure 4. The muscles kept in the potassium-free bath lost still further potassium, while those in the potassium-enriched medium rapidly took up potassium. Despite this large difference in the net movement of potassium, there was no large or significant difference in the apparent efflux of lysine.

\section{DISCUSSION}

These studies were initially undertaken to determine whether cationic amino acids account for the difference between the in vivo and in vitro behavior of muscle potassium as external potassium is lowered. The results show that the addition of lysine to the bath medium does change the potassium equilibrium of isolated muscle in such a way that it resembles more closely that observed during potassium depletion in vivo. However, there are at least two important differences between diaphragms depleted of potassium in vivo and those which lose potassium in a low-potassium medium containing lysine in vitro. In the first place, all of the potassium lost from the muscle in our in vitro system is replaced by lysine, whereas in potassium-depleted rats, cationic amino acids account for no more than one-half of the potassium lost (3). Secondly, sodium enters muscle cells

${ }^{3}$ In these experiments the media designated "potassium-free" or "K-0" were not totally free of potassium. Although no potassium was added, small quantities leaked from the cut ends of the rib cage and intercostal muscles, resulting in final concentrations of approximately 0.1 to $0.2 \mathrm{mEq}$ per L. The final steady-state muscle content of potassium in this "potassium-free" medium is therefore somewhat higher than that shown in Table II for a bath concentration of $0.08 \mathrm{mEq}$ per $\mathrm{L}$; in the latter experiments, but not in the former, frequent changes of medium were employed to keep the external potassium at the desired concentration. 
during loss of potassium in vivo but not in vitro, at external potassium concentrations of $1 \mathrm{mEq}$ per $\mathrm{L}$ or more.

The cationic amino acid concentration of rat plasma is approximately 0.5 to 1 mmole per L; nearly all of this is lysine (3). In the present studies a concentration of 0.8 mmole per $\mathrm{L}$ of lysine in a bathing medium containing $1 \mathrm{mEq}$ per $\mathrm{L}$ of potassium depressed muscle potassium content from 36 to $31 \mathrm{mEq}$ per $100 \mathrm{~g}$ dry weight (Table II). The expected in vivo muscle potassium content at a plasma potassium of $1 \mathrm{mEq}$ per $\mathrm{L}$ is 27.5 mmoles per $100 \mathrm{~g}$ dry weight (1). Thus, a normal plasma level of lysine depresses muscle potassium in vitro about one-half the way toward predicted in vivo levels. Increasing the lysine of the in vitro medium to 2 mmoles per $\mathrm{L}$ depresses muscle potassium content almost to the predicted in vivo level at an external potassium of $1 \mathrm{mEq}$ per L. This concentration of lysine, however, also produces a small but significant decrease in muscle potassium content at an external potassium of 5 $\mathrm{mEq}$ per L. Hence, the effects of this concentration of lysine are not entirely analogous to the in vivo situation.

Since neutral amino acids also have an effect on muscle potassium content (Table I), a number of additional experiments not reported in detail has been performed with mixtures of cationic, neutral, and anionic amino acids in concentrations ranging from one-half to twice those found in normal rat plasma. In each case the effect of the mixture on muscle potassium content was that to be expected from the concentration of cationic amino acid contained in the amino acid mixture. However, no analyses were performed to determine whether some of the potassium lost when mixtures were used was replaced by sodium rather than by cationic amino acid alone.

To summarize the above discussion, the data appear to indicate that the extracellular concentration of cationic amino acids plays an important role in determining the potassium equilibrium of rat skeletal muscle, but amino acids do not entirely account for the previously described differences between the in vivo and in vitro behavior of potassium.

As shown here, cationic amino acids can cause striking potassium loss from rat muscle in vitro. Eckel and co-workers (7), however, reported that potassium was not decreased in normal or potassium-depleted rats by the addition to the diet of large supplements of lysine. These investigators therefore concluded that cationic amino acids act as "mendicant cations" in rat muscle; i.e., cationic amino acids enter muscle when potassium is lost by some other mechanism but cannot themselves force potassium out of skeletal muscle. However, the maximum plasma lysine concentration produced by lysine feeding in their experiments was 1.8 mmoles per L, a figure only slightly above the normal range of 0.5 to 1 mmole per L. Since the present studies show that the magnitude of the potassium loss produced by lysine is a function of its external concentration, it is possible that the relatively low plasma levels attained during lysine feeding account for the failure to demonstrate that lysine can drive potassium out of muscle in vivo. Alternatively, the action of cationic amino acids may be modified in the intact rat by interplay with other factors not present in the simple in vitro system. Studies in which higher plasma lysine concentrations are maintained are needed to evaluate the action of cationic amino acids in vivo.

An extensive series of experiments from Christensen's laboratory has indicated that there is a relation between amino acid transfer and potassium metabolism in mouse Ehrlich ascites tumor cells $(4,8,9)$. In those studies the uptake of one of a variety of neutral or cationic amino acids was associated with some loss of cell potassium. Although there is some similarity in this respect between the tumor cells and our diaphragm preparation, it is difficult to make specific comparisons, since different experimental protocols were employed and different amino acids were studied in detail.

The mechanism of the effect of cationic amino acids on potassium equilibrium in muscle is not clear from these studies. The equivalence between cationic amino acid uptake and potassium loss led us to consider the possibility that potassium, cationic amino acids, and perhaps other cations (e.g., cadaverine) compete for a common carrier or energy supply required for entry into muscle cells. The studies of the effect of lysine on potassium accumulation (Figure 3) were designed to test this hypothesis. External concentrations of lysine as high as 50 mmoles per $\mathrm{L}$ failed to affect the rapid rate of potassium accumulation by muscles previ- 
ously leached of potassium. It therefore seems unlikely that cationic amino acids depress steadystate muscle potassium content by competing with potassium at the cell surface for entry. If there is some relation between amino acid influx and potassium efflux, as suggested by Riggs, Walker and Christensen for Ehrlich tumor cells (4), increased cationic amino acid influx may act at the muscle cell membrane by promoting potassium efflux. Alternatively, cationic amino acids may be transported into muscle cells independently of potassium and cause potassium loss by lowering membrane potential or by competing with potassium for intracellular anionic binding sites.

Certain descriptive features of cationic amino acid transport are shown in Figures 4 and 5. The rate of loss of lysine previously accumulated in rat diaphragm is very slow (Figure 5 ). This indicates both that the (presumably passive) efflux of lysine is very slow, and that net metabolism of lysine in 8 hours is negligible. Since the efflux of lysine was virtually the same, whether or not potassium influx was allowed to occur, it seems unlikely that there is any fixed or obligatory coupling between these two phenomena. The influx of lysine, on the other hand, is much more rapid than its efflux. The maximum rate of lysine accumulation observed in these experiments was about 5 or 6 mmoles per $100 \mathrm{~g}$ dry weight per hour (Figure 4).

\section{SUMMARY}

1. Cationic amino acids markedly decrease the steady-state potassium content of rat skeletal muscle in vitro. Some neutral amino acids have a similar but much less marked effect. Anionic amino acids have no effect.

2. Over the range of external potassium concentrations of 1 to $9 \mathrm{mEq}$ per $\mathrm{L}$, the net loss of muscle potassium caused by lysine is inversely related to external potassium concentration. The net loss of potassium increases as the concentration of lysine in the medium is raised to 4 to 8 mmoles per $\mathrm{L}$, but is not affected by further elevation of medium lysine to 16 mmoles per $\mathrm{L}$.

3. The potassium lost from muscle is replaced by equivalent amounts of lysine. Intracellular sodium and chloride concentrations are essentially unchanged.
4. The net rate of potassium re-entry into muscle previously leached of potassium is not affected by high concentrations of lysine in the external medium.

5. The rate of lysine accumulation by muscle cells is relatively rapid (up to 5 to 6 mmoles per $100 \mathrm{~g}$ dry tissue per hour). On the other hand, the rate of loss of lysine previously accumulated by muscle is very slow and does not appear to be accelerated by potassium influx.

6. It is concluded that the extracellular concentration of cationic amino acids is an important factor influencing the potassium equilibrium of skeletal muscle in the rat. The mechanism by which amino acids exert their effect is not clear, but it seems unlikely that they compete with potassium at the cell surface for entry.

\section{REFERENCES}

1. Relman, A. S., Gorham, G. W., and Levinsky, N. G. The relation between external potassium concentration and the electrolyte content of isolated rat muscle in the steady state. $\mathrm{J}$. clin. Invest. 1961, 40, 386.

2. Iacobellis, M., Muntwyler, E., and Dodgen, C. L. Free amino acid patterns of certain tissues from potassium and/or protein-deficient rats. Amer. J. Physiol. 1956, 185, 275.

3. Eckel, R. E., Norris, J. E. C., and Pope, C. E., II. Basic amino acids as intracellular cations in $\mathrm{K}$ deficiency. Amer. J. Physiol. 1958, 193, 644.

4. Riggs, T. R., Walker, L. M., and Christensen, H. N. Potassium migration and amino acid transport. J. biol. Chem. 1958, 233, 1479.

5. Moore, S., and Stein, W. H. Photometric ninhydrin method for use in the chromatography of amino acids. J. biol. Chem. 1948, 176, 367.

6. Valberg, L. S., and Beveridge, J. M. R. Amino acid pattern in the blood of rats with dietary hepatic necrosis. Canad. J. Biochem. 1960, 38, 365.

7. Eckel, R. E., Pope, C. E., II, and Norris, J. E. C. Influence of lysine and $\mathrm{NH}_{4} \mathrm{Cl}$ feeding on the electrolytes of normal and $\mathrm{K}$-deficient rats. Amer. J. Physiol. 1958, 193, 653.

8. Christensen, H. N., Riggs, T. R., Fischer, H., and Palatine, I. M. Intense concentration of $\alpha, \gamma$-diaminobutyric acid by cells. J. biol. Chem. 1952, 198, 17.

9. Christensen, H. N., and Riggs, T. R. Concentrative uptake of amino acids by the Ehrlich mouse ascites carcinoma cell. J. biol. Chem. 1952, 194, 57. 